УДК 338.1:331.21

JEL: C1; C80; L82; O1

\author{
Іщук Ярослава Володимирівна \\ кандидат економічних наук, доцент, \\ доцент кафедри економіко-математичного моделювання і статистики, \\ Київський національний економічний університет імені Вадима Гетьмана \\ Київ, Україна \\ ORCID ID: 0000-0003-1411-1716 \\ e-mail: yaroslava.ischuk@gmail.com
}

\title{
СТАТИСТИЧНЕ ЗАБЕЗПЕЧЕННЯ КРЕАТИВНОЇ ЕКОНОМІКИ
}

Анотація. Усвідомлення провідної ролі та беззаперечно важливого значення культури в економічній сфері призвело до виникнення креативної економіки. Особливістю креативної економіки $є$ те, що в її основі знаходиться «духовна» складова, яка зберігається та передається за допомогою людської творчості, культури та унікального (креативного) бачення звичних речей. В свою чергу це дало потужний поштовх для подальшого соціально-економічного розвитку в усьому світі, але уже в рамках креативної економіки. Стрімкий розвиток цифровізації посприяв не менш стрімкому розвиткові креативних індустрій, які було згруповано у сектори креативної економіки, що частково взаємодіють між собою.

Вивчення та оцінювання креативних індустрій сьогодні не є достатнім і часто обмежене, що пояснюється відсутністю необхідних для глибокого дослідження даних. Існуюче статистичне забезпечення наразі не може задовольнити потреби дослідників у даних, які характеризуються оперативністю та унікальністю, що в першу чергу обумовлюється специфікою цих індустрій, де матеріальна складова тісно поєднана 3 «духовною».

У статті досліджено теоретико-методологічні засади креативної економіки. Зазначено, що розробка та впровадження Нової європейської програми з культури має важливе значення для подальшого розвитку і становлення креативних індустрій. Проаналізовано та виявлено недоліки в існуючій системі статистичних показників, яка характеризує креативну економіку.

На основі проведеного дослідження статистичного забезпечення креативної економіки зроблено висновок про доцільність імплементації Індексу щастя у методологію оцінювання Глобального індексу креативності, а також використання big data для удосконалення вивчення креативних індустрій, 3 метою отримання грунтовних, унікальних та специфічних даних для подальшого оцінювання цієї категорії індустрій.

Ключові слова: статистичне забезпечення; система показників; креативна економіка; сектори креативної економіки; креативні індустрії; Глобальний індекс креативності.

\section{DOI: http://doi.org/10.32750/2020-0204}

\section{ВСТУП}

Постановка проблеми. У процесі дослідження будь-якого питання, перш за все необхідно дослідити його інформаційне та статистичне забезпечення. Незважаючи на те, що тема креативної економіки уже близько двадцяти років обговорюється у наукових колах, iі статистичне забезпечення потребує нових грунтовних досліджень 3 метою виявлення нових джерел даних, які допомогли б різносторонньо проаналізувати іiі сектори, шляхом представлення повної і структурованої системи статистичних показників, яка б забезпечила їх подальше об'єктивне вивчення. Зазначене обумовило написання цієї статті та визначило ключові аспекти дослідження.

Аналіз останніх досліджень і публікацій. Дослідженням питань креативної економіки було присвячено наукові роботи таких науковців: Вахович I. [1], Горобець О. [2], Гринчук Ю. [3], Давимука С. [4], Коваль Н.[3], Мелландер К. [6], Родіонова І.[5], Федулова Л.[4], Флорида Р.[6], Чуль О. [1] та ін. В рамках дослідження використовувалися ресурси Євростату, ЮНКТАДу (UNCTAD) та ін.

Метою статті $є$ дослідження статистичного забезпечення креативної економіки. 


\section{ТЕОРЕТИЧНІ ОСНОВИ ДОСЛІДЖЕННЯ}

Креативна економіка поєднує у собі товари та послуги, які виникли у результаті творчості та креативного мислення. Ядром креативної економіки є людські цінності. Появі креативної економіки сприяла цифровізація. Швидкий розвиток інформаційнокомунікаційних технологій призвів до так званої «безкордонності», якому посприяли інтернет-ресурси та глобалізованість англійської мови як міжнародної, у результаті чого став можливий безперешкодний обмін ідеями, спілкування між людьми 3 усього світу, доступність різного роду цифрових ресурсів ті ін. Усе це призвело до стрімкого зростання та поширення культурних товарів та послуг.

Досліджуючи теоретико-методологічні засади та практичні аспекти креативної економіки Давимука С. та Федулова I. зазначають, що «сьогодні визнаним лідером у креативній економіціє Великобританія, яка розробила і продовжує розробляти правову базу, стратегічні і політичні документи розвитку національної економіки через економічну, культурну і соціальну взаємодію»[4].

У 2008 р. у звіті ЮНКТАД було виокремлено 9 секторів креативної економіки, які є креативними індустріями (рис. 1).

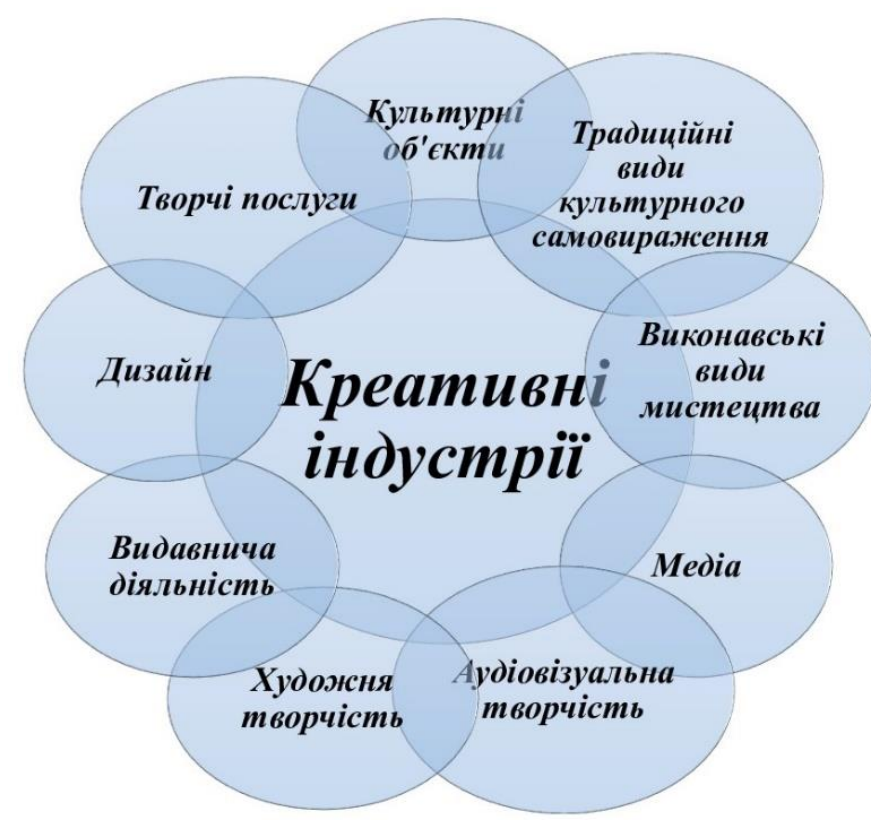

Рис. 1. Сектори креативної економіки

Джерело: сформовано автором за [7].

Так, до сектору Культурні об'єкти відносять залишки древніх поселень, твори архітектури, унікальні ландшафти; до Традиційних видів культурного самовираження форми самовираження, які випливають 3 творчості окремих осіб або груп та мають культурну цінність; до Виконавських видів мистецтва - «тимчасово-просторові» види мистецтва; до Медіа - інформаційно-комунікаційні засоби; до Аудіовізуальної творчості - створення музичних та кінотворів; до Художньої творчості - весь процес роботи над культурним твором, незалежно від виду мистецтва (діяльність як письменника так і композитара та художника); до Видавчничої діяльності - книговидання, видання газет і журналів, видання програмного забезпечення та комп'ютерних ігор; до Дизайну художньо-предметне мистецтво та інженерну практику у сфері індустріального виробництва; до Творчих послуг - послуги у сфері культури. Виходячи із зазначеного, варто зауважити, що у кожному із зазначених секторів поєднується як творча 
(культурна) так і матеріальна (економічна) складові, що в свою ускладнює моніторинг їхнього розвитку, адже зазначені на рис. 1 індустрії креативної економіки поєднують у собі різні види даних, що статистично характеризують кожну індустрію окремо. Також усі зазначені сектори взаємодіють між собою, створюючи при цьому унікальні або ж дубльовані дані (наприклад, під час написання комп'ютерної гри використовують аудіотвір та ін.). Зауважимо, що наразі Свростат визначає культуру рушієм економічного розвитку, що сприяє економічному зростанню, добробуту людей та соціальній згуртованості в Європі.

Враховуючи зазначене, у рамках статистичного дослідження книговидавництва (креативна індустрія - видавнича діяльність (рис. 1)), Горобець О. О. зазначає, що у своїй діяльності органи державної статистики повинні удосконалювати технології збирання інформації, забезпечувати збереження, захист та конфіденційність статистичної інформації та пропонує використовувати big data для удосконалення системи статистичних показників книговидавництва [2].

3 метою забезпечення основи для співпраці у галузі культури на рівні ЄС було розроблено Нову європейську програму з культури, цілі якої можна розділити за трьома вимірами: соціальний, економічний, зовнішній (рис.2).

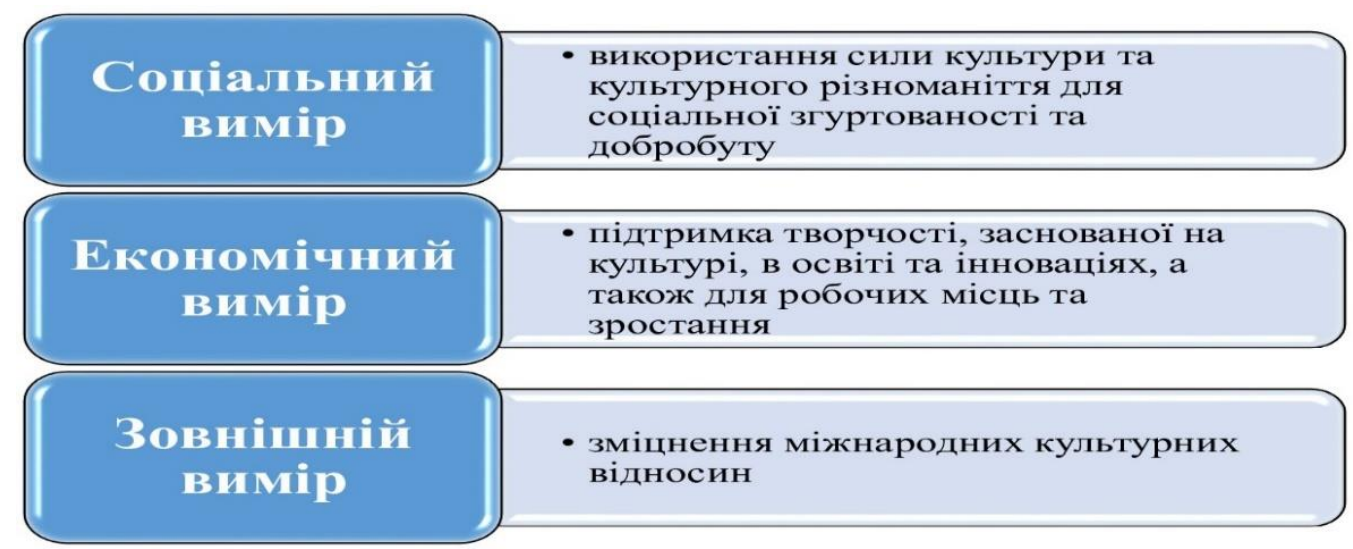

Рис. 2. Стратегічні цілі Нової європейської програми з культури Докерело: згруповано автором за [8].

Метою цієї програми $є$ заохочення мобільності професіоналів у культурному та творчому секторах, захист та просування європейської культурної спадщини як спільного ресурсу, сприяння у розвитку мистецтва і безпосередньо, творчому мисленню протягом усього життя, сприяння розвитку комфортних для культурних та творчих галузей екосистем, а також надавати підтримку культурі як двигуну сталого соціального та економічного розвитку.

Виходячи із структури рис. 2 та інтерпретуючи цілі у складові культурного товару, доцільно зауважити, що поєднання у культурному товарі (або послуги) складових які б задовольняли соціум, були б економічно вигідним не лише в межах однієї країни, а на міжнародному ринку, забезпечить популярність у еквіваленті прибутковості не лише товару, а й виробнику та галузі в цілому.

У цьому контексті, доцільно навести думки дослідників, які займаються вивченням вітчизняної креативної економіки.

Так, Гринчук Ю. та Коваль Н. аналізуючи креативний потенціал України зазначають, що для покращення позицій України у міжнародних рейтингах за результатами індексів, необхідно в першу чергу об'єднати зусилля держави, органів 
місцевого самоврядування, бізнесу, громадських організацій [3]. Вахович I. та Чуль О. у результаті проведеного аналізу стану креативного регіонального розвитку України в розрізі індустрій креативної економіки ствержують, що при розробці стратегій креативного регіонального розвитку для усіх без винятку регіонів варто враховувати те, що креативна економіка тісно пов'язана із суспільною, культурною, науково-технічною, екологічною та іншими сферами народного господарства [1]. Родіонова I. аналізуючи теоретичні засади політичних стратегій соціально-економічного розвитку міста в умовах інноваційної економіки, звертає увагу на те, що здатність суспільств та окремих міст генерувати та використовувати креативність людини, у той же час мінімізуючи відповідні інноваційні ризики, $\epsilon$ вимогою сучасності та умовою їхньої конкурентноспроможності на глобальній арені [5].

У звіті ЮНКТАД зазначено, що чисельність зайнятого населення України у сфері креативної економіки складає 470 тис. Разом 3 тим, представлено дані, які характеризують потенціал України у сегменті креативної економіки. Зі звіту, експорт креативних товарів України зріс утричі з 239 млн дол. США у 2005 р. до 768 млн дол. США у 2014 р., що продемонструвало потужний потенціал креативної економіки України. Викликає зацікавленість те, що найбільшу частку експорту становили дизайнерські товари. Імпорт товарів для творчості у 2014 р. становив 769 млн дол. США. 3 цього можна стверджувати, що ринок вітчзняної індустрії моди масштабувався до рівня світового, про це також свідчить популярність українських дизайнерів за кордоном. Основними партнерами України в експортно-імпортних відносинах були Свропа та Азія. Так, у 2014 р. у п’ятіркою експортних партнерів України для креативних товарів були Російська Федерація, Казахстан, Білорусь, Данія, Азербайджан. Варто зазначити, що у 2014 р. експорт креативних послуг становив 2,1 млрд дол. США [9].

Варто зазначити, що одним із пріоритетних напрямів розвитку України на період 3 2017 по 2021 рік стала підтримка сектору видавничої діяльності, а саме розвиток IT (створення програмного забезпечення та ін.).

Флорида Р. та ін., розробляючи методологію Глобального індексу креативності виокремлює такі показники креативної економіки: відсоток працівників креативного класу у загальній кількості зайнятих, відсоток осіб, що здобувають освіту професійнотехнічну, вищу), обсяг інвестицій у науково-дослідну та науково-конструкторські роботи, заявки на пантенти, відсоток респондентів які вважають, що населений пункт у якому вони проживають $є$ хорошим місцем для етнічних і расових меншин, відсоток тих, хто повідомляє, що їхній населений пункт є хорошим місцем для проживання геїв та лесбійок [6]. Варто зазначити, що Глобальний індекс креативності розраховується за допомогою інших глобальних індексів, серед яких: Глобальний індекс талантів, Глобальний індекс технологій та Індекс толерантності. Виходячи з цього, основними складовими, які формують креативний потенціал кожної країни є рівень обдарованості населення (таланти), рівень розвитку цифровізації (технології) та телорантність іiі населення та уряду. У 2015 р. в першу п’ятірку країн за рівнем Глобального індексу креативності входили Австралія $(0,970)$, США $(0,950)$, Нова Зеландія $(0,949)$, Канада $(0,920)$ та Швеція $(0,917)$. Україна у цьому рейтингу посідала 45 місце, наступними після України були Польща, Чорногорія та Болгарія [10]..

Зауважимо, що Євростат досліджує та надає статистичну оцінку секторам креативної економіки, а також займається координацією та гармонізацією статистичних даних про сектори культури та творчості в рамках статистики культури. Виходячи 3 цього, вважаємо за доцільне звернутися до методологічних рекомендацій, статистичних оглядів та аналітичних звітів Свростату у якому креативні індустрії представлені через призму статистичних показників (рис. 3). 


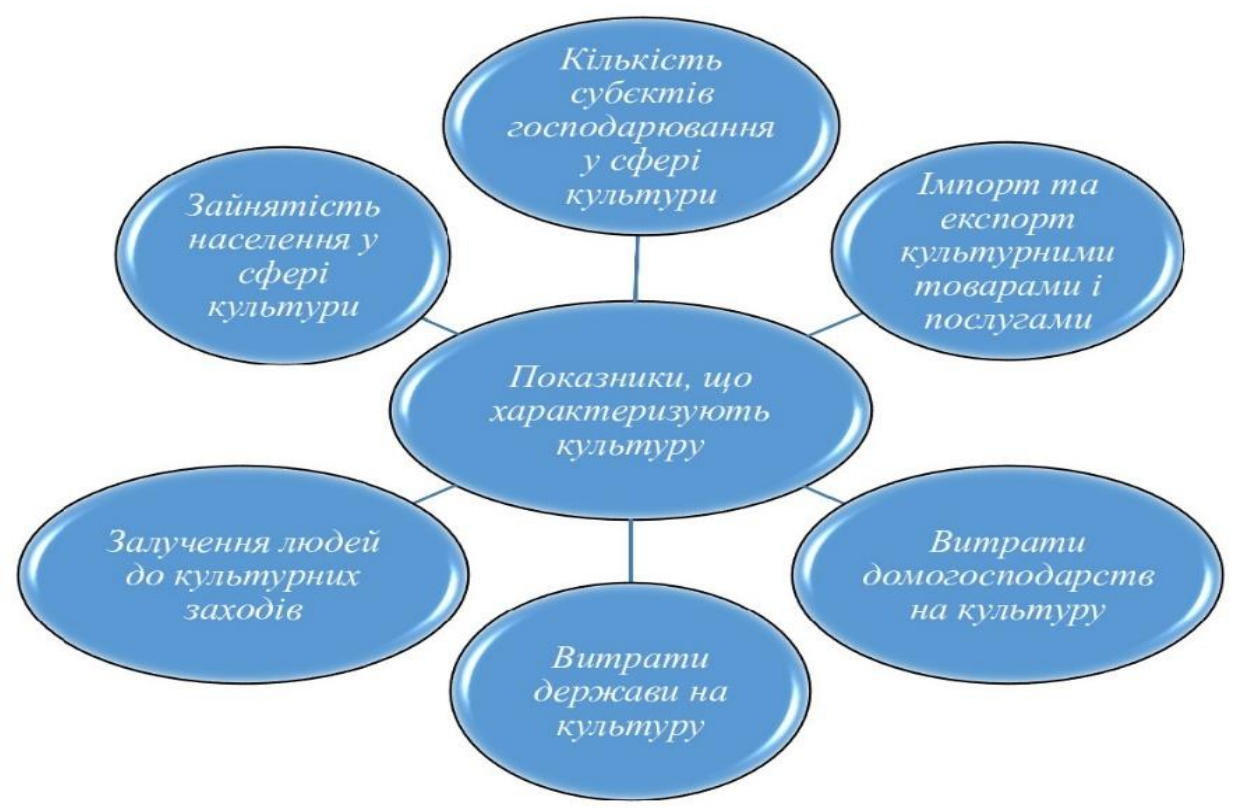

Рис. 3. Статистичні показники, які характеризують культуру

Джерело: побудовано автором за [11].

3 рис. 3 можна зробити висновок про те, що Євростат у підготовці статистичної інформації використовує показники, які свідчать лише про економічну складову галузі i не враховують ії специфіку, тобто показники, які б надавали інформацію про невід’ємну для креативної економіки - творчу складову.

\section{РЕЗУЛЬТАТИ ДОСЛІДЖЕННЯ}

Виходячи із теоретичного підгрунтя цього дослідження, варто зауважити, що попри сформовану систему показників Свростату та показників і субіндексів, що формують Глобальний індекс креативності, наявна система статистичних показників недостатньо повно та «збалансовано» відображає сучасний стан креативних індустрій, разом з цим, вона дає надійну основу для подальшого ії удосконалення.

Так, за результатами дослідження пропонується удосконалення методології Глобального індексу креативності шляхом імплементації Індексу щастя, який обчислюється за допомогою трьох показників: суб'єктивна задоволеність життям людьми, очікувана тривалість життя та «екологічний слід» людини. Доказовою базою запропонованого $є$ загальновідомі твердження про те, що почуття щастя, задоволеність життям та сформоване при цьому світосприйняття, є важливою стороною психічного стану людини, яке покращує або навпаки, пригнічує творчість та креативне мислення [12].

Також доцільним $є$ використання big data як альтернативного джерела статистичних даних, з метою розширення наявної системи статистичних показників для більш глибокого оцінювання креативних індустрій та впровадження індивідуальних, для кожного сектора, статистичних показників. У цьому випадку варто зазначити, що використовувати Big Data у статистичному розрізі варто з обережністю - не порушуючи в той же час конфіденційність та дбаючи про їхню захищеність під час обробки та подальшого аналізу. 


\section{ВИСНОВКИ ТА ПЕРСПЕКТИВИ ПОДАЛЬШИХ ДОСЛІДЖЕНЬ}

3 проведеного дослідження можна зробити висновок про те, що той теоретичний базис, який створено за допомогою досліджень як вітчизняних так і закордонних вчених $\epsilon$ надійним підгрунтям для подальшого вивчення та аналізу креативної економіки, а розробка нових підходів до моніторингу та оцінювання надасть можливість у повній мірі досліджувати креативні індустрії та сприяти їхньому розвитку.

Перспективами подальших досліджень буде проведення грунтовного аналізу специфіки креативних індустрій та вивчення досвіду використання альтернативних джерел даних для статистичного забезпечення креативної економіки.

\section{СПИСОК ВИКОРИСТАНИХ ДЖЕРЕЛ}

1. Вахович I. М., Чуль О. М. Формування стратегічних орієнтирів креативного регіонального розвитку на основі кластерного аналізу. Бізнес Інформ. 2014. № 9. С. 57-65. URL: http://irbisnbuv.gov.ua/cgi-

bin/irbis_nbuv/cgiirbis_64.exe?I21DBN=LINK\&P21DBN=UJRN\&Z21ID=\&S21REF=10\&S21CNR=20\&S21S $\mathrm{TN}=1 \& \mathrm{~S} 21 \mathrm{FMT}=\mathrm{ASP} \_$meta\&C21COM=S\&2_S21P03=FILA=\&2_S21STR=binf_2014_9_10.

2. Horobets O. (2020). Alternative Sourses Of Information To Support a Set of Statistical Indicators of The Book Publishing. International Journal of Innovative Technologies in Economy, (5 (32)). Retrieved from: https://rsglobal.pl/index.php/ijite/article/view/1764. doi: https://doi.org/10.31435/rsglobal_ijite/30122020/7284.

3. Гринчук Ю. С., Коваль Н. В. Креативний потенціал України: аналіз, напрями розвитку. Економіка та держава. 2020. №7. URL: http://www.economy.in.ua/pdf/7_2020/3.pdf.

4. Давимука С. А., Федулова Л. І. Креативний сектор економіки: досвід та напрями розбудови: моногр. ДУ «Інститут регіональних досліджень імені М. І. Долішнього НАН України». Львів, 2017. С. 35. URL: https://ird.gov.ua/irdp/p20170702.pdf.

5. Родіонова I. О. Місто у добу креативності: до визначення теоретичних засад політичних стратегій соціально-економічного розвитку. Сучасне суспільство. 2015. Вип. 1(2). С. 132-146. URL: http://www.irbis-nbuv.gov.ua/cgi-

bin/irbis_nbuv/cgiirbis_64.exe?I21DBN=LINK\&P21DBN=UJRN\&Z21ID=\&S21REF=10\&S21CNR=20\&S21S $\mathrm{TN}=1 \& \mathrm{~S} 21 \mathrm{FMT}=\mathrm{ASP} \_$meta\&C21COM=S\&2_S21P03=FILA=\&2_S21STR=cuc_2015_1(2)_15.

6. Florida R., Mellander C. and King K. The Global Creativity Index 2015. Martin Prosperity Institute. 68 p. URL: http://martinprosperity.org/wp\$content/uploads/2015/07/Global\$Creativity\$Index\$2015.pdf.

7. United Nations. UNCTAD. (2008). Creative Economy. Report 2008. Retrieved from: https://unctad.org/system/files/official-document/ditc20082cer_en.pdf.

8. European Commission. EUR-Lex home. Communication From The Commission To The European Parliament, The European Council, The Council, The European Economic and Social Committee and The Committee of The Regions. A New European Agenda for Culture. COM/2018/267 final. Document 52018DC0267. $\quad$ Retrieved from: https://eur-lex.europa.eu/legalcontent/EN/TXT/?qid=1527241001038\&uri=COM:2018:267:FIN.

9. United Nations. UNCTAD. Creative Economy Outlook. Trends in international trade in creative industries 2002-2015. Country Prifiles 2005-2014. Retrieved from: https://unctad.org/system/files/officialdocument/ditcted2018d3_en.pdf.

10. Top-25 Countries On The Global Creativity Index/ Retrieved from: https://www.culturepartnership.eu/en/article/global-creativity-index-2015.

11. Eurostat. Database. Culture. Retrieved from: https://ec.europa.eu/eurostat/web/culture/data.

12. The Un Happy Planet Index 2.0. Why good lives don't have to cost the Earth. Retrieved from: https://base.socioeco.org/docs/the_happy_planet_index_2.0_1.pdf. 


\section{Ищук Ярослава Владимировна}

кандидат экономических наук, доцент, доцент кафедры экономико-математического моделирования и статистики, Киевский национальный экономический университет имени Вадима Гетьмана Киев, Украина

ORCID ID: 0000-0003-1411-1716

e-mail: yaroslava.ischuk@gmail.com

\section{СТАТИСТИЧЕСКОЕ ОБЕСПЕЧЕНИЕ КРЕАТИВНОЙ ЭКОНОМИКИ}

Аннотация. Осознание ведущей роли и неоспоримо важного значения культуры в экономической сфере привело к возникновению креативной экономики. Особенностью креативной экономики является то, что в ее основе находится «духовная» составляющая, которая хранится и передается с помощью человеческого творчества, культуры и уникального (креативного) виденья привычных вещей. В свою очередь, это дало мощный толчок для дальнейшего социально-экономического развития во всем мире, но уже в рамках креативной экономики. Стремительное развитие цифровизации содействовало не менее стремительному развитию креативных индустрий, которые были сгруппированы в секторы креативной экономики, частично взаимодействующие между собой.

Изучение и оценивание креативных индустрий сегодня не является достаточным и часто ограничено, что объясняется отсутствием данных, необходимых для глубокого исследования. Существующее статистическое обеспечение в данный момент не может удовлетворить потребности исследователей в данных, характеризующихся оперативностью и уникальностью, что в первую очередь обусловлено спецификой этих индустрий, где материальная составляющая тесно соединена с «духовной».

В статье исследованы теоретико-методологические принципы креативной экономики. Отмечено, что разработка и внедрение Новой европейской программы по культуре имеет важное значение для дальнейшего развития и становления креативных индустрий. Проанализированы и выявлены недостатки в существующей системе статистических показателей, которая характеризует креативную экономику.

На основе проведенного исследования статистического обеспечения креативной экономики сделан вывод о целесообразности имплементации Индекса счастья в методологию оценивания Глобального индекса креативности, а также об использовании big data для усовершенствования изучения креативных индустрий, с целью получения основательных, уникальных и специфических данных для дальнейшего оценивания этой категории индустрий.

Ключевые слова: статистическое обеспечение; система показателей; креативная экономика; секторы креативной экономики; креативные индустрии; Глобальный индекс креативности. 


\author{
Ishchuk Yaroslava \\ $\mathrm{PhD}$ in Economics, \\ Assistant professor at the Department of Economic and Mathematical Modeling and Statistics, \\ SHEE «Kyiv National Economic University named after Vadym Hetman», \\ Kyiv, Ukraine \\ ORCID ID: 0000-0003-1411-1716 \\ e-mail:yaroslava.ischuk@gmail.com
}

\title{
STATISTICAL SUPPORT FOR THE CREATIVE ECONOMY
}

Abstract. The awareness of the prominent role and indisputably great importance of culture in the economic domain led to the emergence of the creative economy. A specific feature of the creative economy is that it rests on "spiritual" component that is preserved and passed by means of human creativity, culture and unique (creative) perceptions of routine things. This could give a powerful impulse to the socio-economic development across the world, furthered in the creative economy framework. The rapid development of digitalization triggered the not less rapid development of creative industries grouped into creative economy sectors partially interacting with each other.

Studies and assessments of creative industries are now insufficient and often limited, which can be explained by lack of the data required for the extensive research. The existing statistical support is incapable to meet the needs of researchers requiring the data characterized by timeliness and uniqueness, which is caused, by far and large, by the specificity of these industries where the material component is closely linked with the "spiritual" one.

Theoretical and methodological foundations of the creative are investigated in the article. It is argued that elaboration and implementation of the New European Program on Culture has great importance for further development and formation of creative industries. The shortcomings of the existing set of statistical indicators characterizing the creative economy are revealed and analyzed.

Based on the author's study of the statistical support for the creative economy, the conclusion is made that it is advisable to implement the Index of Happiness in the methodology for assessment of the Global Creativity Index and use big data to improve creative industries' research, in order to obtain sound, unique and specific data for further assessment of this category of industries.

Keywords: statistical support; set of indicators; creative economy; creative economy sectors; creative industries; Global Creativity Index.

\section{REFERENCES}

1. Vakhovych I. M., Chul O. M. (2014). Formuvannia stratehichnykh oriientyriv kreatyvnoho rehionalnoho rozvytku na osnovi klasternoho analizu [Forming strategic orientations for the creative regional development on the basis of cluster analysis]. Bisnes Inform - Business Inform, 9, 57-65. Retrieved from http://irbis-nbuv.gov.ua/cgi-

bin/irbis_nbuv/cgiirbis_64.exe?I21DBN=LINK\&P21DBN=UJRN\&Z21ID=\&S21REF=10\&S21CNR=20\&S21S $\mathrm{TN}=1 \& \mathrm{~S} 21 \mathrm{FMT}=\mathrm{ASP} \_$meta\&C21COM=S\&2_S21P03=FILA=\&2_S21STR=binf_2014_9_10. [in Ukrainian].

2. Horobets O. (2020). Alternative Sources of Information to Support a Set of Statistical Indicators of the Book Publishing. International Journal of Innovative Technologies in Economy, (5 (32)). Retrieved from: https://rsglobal.pl/index.php/ijite/article/view/1764. doi: https://doi.org/10.31435/rsglobal_ijite/30122020/7284. [in English]

3. Hrynchuk Yu. S., Koval N. V. (2020). Kreatyvnyi potentsial Ukrainy: analiz, napriamy rozvytku [Creative potential of Ukraine: analysis, development directions]. Ekonomika ta derzhava - Economy and the State, 7. Retrieved from http://www.economy.in.ua/pdf/7_2020/3.pdf. [in Ukrainian].

4. Davymuka S. A., Fedulova L. I. (2017). Kreatyvnyi sektor ekonomiky: dosvid ta napriamy rozbudovy [The creative sector of the economy: experience and components of formation]. Lviv: Dolishniy Institute of Regional Research of the NAS of Ukraine, p. 35. Retrieved from https://ird.gov.ua/irdp/p20170702.pdf. [in Ukrainian].

5. Radionova I. O. (2015). Misto u dobu kreatyvnosti: do vyznachennia teoretychnykh zasad politychnykh stratehii sotsialno-ekonomichnoho rozvytku [The city in the creativity era: outlining theoretical foundations for political strategies of socio-economic development]. Suchasne suspilstvo - Modern Society, vol. 2, issue 9. Retrieved from http://www.irbis-nbuv.gov.ua/cgibin/irbis_nbuv/cgiirbis_64.exe?I21DBN=LINK\&P21DBN=UJRN\&Z21ID=\&S21REF=10\&S21CNR=20\&S21S $\mathrm{TN}=1 \& S 21 \mathrm{FMT}=\mathrm{ASP} \_$meta\&C21COM=S\&2_S21P03=FILA=\&2_S21STR=cuc_2015_1(2)_15 [in Ukrainian]. 
6. Florida R., Mellander C., and King K. The Global Creativity Index 2015. Martin Prosperity Institute. 68 p. Retrieved from http://martinprosperity.org/wp\$content/uploads/ 2015/07/Global\$Creativity\$Index\$2015.pdf. [in English]

7. United Nations. UNCTAD. (2008). Creative Economy. Report 2008. Retrieved from https://unctad.org/system/files/official-document/ditc20082cer_en.pdf. [in English]

8. European Commission. EUR-Lex home. Communication From The Commission To The European Parliament, The European Council, The Council, The European Economic and Social Committee and The Committee of The Regions. A New European Agenda for Culture. COM/2018/267 final. Document 52018DC0267. Retrieved from https://eur-lex.europa.eu/legalcontent/EN/TXT/?qid=1527241001038\&uri=COM:2018:267:FIN. [in English]

9. United Nations. UNCTAD. Creative Economy Outlook. Trends in international trade in creative industries 2002-2015. Country Profiles 2005-2014. Retrieved from https://unctad.org/system/files/officialdocument/ditcted2018d3_en.pdf. [in English]

10. Top-25 Countries On The Global Creativity Index/ Retrieved from https://www.culturepartnership.eu/en/article/global-creativity-index-2015. [in English]

11. Eurostat. Database. Culture. Retrieved from https://ec.europa.eu/eurostat/web/culture/data. [in English]

12. The Un Happy Planet Index 2.0. Why good lives don't have to cost the Earth. Retrieved from: https://base.socioeco.org/docs/the_happy_planet_index_2.0_1.pdf. [in English] 